\title{
The Evolution of Architectural Culture of Harbin under the Dual Structure Characteristics
}

\author{
Jiang Xue \\ Design and Art School, Harbin University of Commerce, Heilongjiang, China
}

Keywords: Russian architecture; Dual structure; Fusion.

\begin{abstract}
Harbin is a distinctive new modern city formed under certain historical conditions. Under the impact of dual structure characteristics, the urban architectures system in modern Harbin not only embodies the renaissance of Chinese traditional architecture, but also reflects the development trend of European architecture art, it is a product of conflicts and integration between Chinese traditional culture and European architecture thoughts. The biggest characteristics of Harbin city is diversified architecture of Russian. When protecting, and promoting the distinctive architectural style, the coordination of architectural function and urban planning and development should be considered at first. Through the protection and renewal of Russian style architecture in Harbin, to promote the development of Harbin in the future and retain its original architecture culture connotation at the same time, it is necessary to formulate corresponding sustainable development and protection measures of urban architecture.
\end{abstract}

\section{Introduction}

A city's vicissitudes of life and historical changes can be reflected from the architecture of the city. During the past few decades, Harbin has developed into a famous new modern city from a small fishing village, modern urban architecture in Harbin also witnessed the development and transformation of this history. Through the research on urban architecture of Harbin, the development and transformation vein and the cultural connotation of this city could be combed. Harbin is a city with unique style, and its city image is different from the traditional city in China because of internal and external factors. However, what is the reason for these diversified characteristics of the urban architecture of Harbin? Since the eighteenth century, the urban architecture of Harbin has a strong group of western architectural style, the traditional Chinese architectural style, Japanese architecture style and Islamic architecture style. The Chinese Baroque style combines traditional Chinese architecture culture and western architecture culture and forms the unique architectural culture style of Harbin, which led to the diversified characteristics of urban architecture of Harbin.

\section{Characteristics of urban architectural culture of Harbin}

Throughout history, each country, nation and city has its own multicultural connotation. Under this connotation, they express personality characteristics, and even a kind of spirit. The architectural culture of modern Harbin has formed under a special background, and this background led to a unique personality of Harbin architectural culture which is different from most of the traditional city in China.

In Chinese history, Harbin is a young city with only more than one hundred years, and a typical immigrant city, formerly known as Agri kam, and is called Halabin in Qing dynasty. In the late nineteenth and early twentieth centuries, Russia built the Middle East railway which brought a lot of Russian immigrants, and make the emerging city Harbin accepted the baptism of the architectural culture which is different from tradition Chinese. In this developing process, Harbin forms itself unique architectural style which is different from traditional Chinese city, and contains the stronger advanced consciousness to introduce new design idea in the aspect of urban construction. Harbin is different from any city of China, although it doesn't have a long history like other domestic cities, but it has a unique architectural style. The Russian immigrants at that time replicated the Moscow city construction to Harbin, so the city Harbin mixed with exotic blood and architectural culture. Even if time passes, until one hundred years later, the city still bears the hallmarks of Russian culture. In 
Harbin, the blending of Chinese and Western cultures, and the blending of Chinese and Western architectural culture behave very strongly.

In the architectures with regional characteristics in Harbin, there are Russian style architecture, Russian Baroque architecture, France fashionable style architecture, European classical architecture, and Russian wooden architecture, and few Chinese architecture and Japanese architecture in the 30s.

\section{The dual structure characteristics of the modern architectural culture in Harbin}

Most cities in China are affected by the feudal traditional culture thought, and gradually to the prototype of the modern city. First, a part of the port cities introduces the advanced western modern culture under the attraction of external force initially, to gradually close to the urban modernization process. However, most of the inland cities which far away from the trading ports are keep feudal traditional thoughts and short of modern urban atmosphere. In this way, the advanced modern urban culture is bound to encounter many barriers and difficulties in these conservative and backward regions, therefore, the traditional culture and foreign culture, the traditional agricultural civilization and the modern industrial civilization are opposite and mingled to each other, this type of dual structure characteristics has formed. In modern Harbin, more than one hundred years ago, the advanced western architectural culture which brought by a larger number of Russian immigrants and Harbin local conservative and backward culture were collided with each other, it is the embodiment of this dual structure. Such as the Chinese Baroque architectures in Daowai district of Harbin, the architectural form is China's courtyard layout structure, but the architectural technology adopts Russian. It is not only the fusion of Chinese and western architecture, but also the fusion of diversified architectural styles of western, to form a complex with various architectural culture individuals integrated with each other. This kind of unique Chinese baroque architecture, adopts the facade composition of western architecture and integrates Chinese traditional auspicious decorative grain type at the same time. The facades of these architectures adopt western common architectural style, such as baroque broken eaves, classical pillar type, pediment and patchwork parapet wall and so on, and these construction components integrate with some detail characteristics of Chinese traditional architecture, such as brackets, drum type pillar base and so on.

\section{The concrete representation of dual structure characteristics in Harbin architectural culture}

The concrete representation of dual structure characteristics in Harbin architectural culture is: First is the coexistence of Chinese traditional culture and western external culture. The positive influence of this coexistence is to provide a chance for Chinese and Western culture to blend with each other in city. Modern western capitalist culture represents the industrial civilization, for the most part to promote and introduce some advanced culture thoughts into modern Chinese cities. These thoughts accelerate the pace of city modernization transformation. Making these cities can contact with the culturally advanced cities in the world, and speed up the promotion of urban culture. Second is the coexistence of urban culture and rural culture. On the one hand, the coexistence of the two cultures restricts the transformation of urban culture. In most of the modern Chinese cities, because of the slow process of modernization of Chinese society, and the imbalance and mutilation of urbanization itself, the rural culture haven't back out form the areas of advanced urban culture thoroughly because of its own refractoriness. Most areas which turn into the modern transformation of urbanization early are still surrounded by traditional rural environment.

The urban culture and architectural culture of modern Harbin not only has the common characteristics above-mentioned, but also has its own unique personality. The collision and coexistence of Chinese and western culture reflects in Daowai district of Harbin, and this coexistence reflects the gentle collision between Chinese and western traditional culture. Due to the same level, it can smoothly integrate as a unique architectural complex between Chinese and Western. In Nangang district and Daoli district, most architectures have the dual structure characteristics which is the coexistence between the old and new cultural systems in the west and Russian cultural system 
modeled on the west. But we can see the Chinese traditional culture, the squire culture and village culture have definite influence on the urban culture and architectural culture of Harbin. This kind of unique dual culture structure characteristics is the footstone which constructs the unique architectural culture landscape of Harbin.

In early Harbin, at that time, only pier area, some new urban regions and some old architectures, these are churches and temples with extremely rich architectural history research value. It is lucky that these ancient architectures have been protected up to now, and still intact. These architectures make the modern city Harbin has strong Russian style, however the color is waning year after year. The most distinction between modern office building and Harbin old buildings built in the early $20^{\text {th }}$ century is the former could not let people to enjoy the ancient imposing beauty. The construction pace of modern Harbin is close to these ancient buildings step by step, and encroach on it ultimately and relentlessly.

When we recall the history of Harbin again, we only see its debris. Today, people has revived the beautiful idea of this ideal city by research, reminiscence and description. We must trust that the interrelated thesis of the world proletarian mentor Lenin is the irrefutable truth forever. He said, no matter how to destroy a kind of culture, it is impossible to wipe away from the history lives completely. Although it is very difficult to restore it, but it could not be disappeared by any destroys at any time. It has remained in the form of one way or the other material remains, and difficult to return to the original state.

When discussing and researching the architectural style of Harbin, we know that many precious architectures with individual style have been dismantled and destroyed. And now some of the new architectures are modelling on the past architectures roughly sometimes which are neither fish nor fowl. In this case, is due to some mistakes which caused by lack of knowledge of the origin development of urban architectural style. So, it is necessary to research and discuss the historical style of urban architectures and will play a large role to benefit from the urban construction. In interview of Lv Fuxun, the professor and PHD supervisor at Tsinghua University's school of architecture, he thinks that to overall shape the architectural style of Harbin is very difficult, Harbin has many western architectural monuments, to create its architectural style should be based on architectural monuments protection. Combined with the needs of the current urban development and city life to create a new Harbin architectural style which full of ethos of the times. This style should be combined with the current economy, technology and people's aesthetic demand. Only in this way can reflect the mental attitude of Harbin which should reflected by its urban landscape in this era.

To grasp the historical context does not mean to model on ancient architectures largely. The ancient architectures should keep their original features, and new architectures are new modern architectures, not fake antique architectures which obliterate the process of time. Architecture should faithfully reflect the culture of a period at the time, so the house built in the early years of the $21^{\text {st }}$ century should be different from the house built in the early years of the $20^{\text {th }}$ century, to reflect the changes of The Times. We can't just lie in the traditional architectural culture. Architecture is closely related to the age, we can look at our country, such as the architectures in the early liberation days, the architectures in the period of reform and opening-up, and including the present contemporary architectures, all have very strong characteristics of The Time, different time, different materials, different construction technology level and different aesthetic value orientation. Urban style couldn't achieve the level what we want to pursuit subjectively. From south to north, Guangzhou, Shanghai, Harbin, it is hard to find the city characteristics are different from other cities in the city. If one day, Eastern Paris and Eastern Moscow no longer appears in the brochure of Harbin, the city style of Harbin has self-confidence, and Harbin will return to Harbin. Today, our cities are lack of confidence, because imitating foreign cities further such as comparing Suzhou to Venice. But think carefully, what is the age of Venice, and what is the age of Suzhou? This is the performance of wrong attitude of its own tradition, culture and civilization. therefore, we have to create our own style, Harbin has its unique multicultural architectural background, as a urban architectural style, we couldn't revival Moscow style, if we pursued that kind of urban style blindly, it would be very dangerous for Harbin itself. 
Harbin has its own history and connotation, but there should be some subsequent architectures, ancient architectures should be preserved without big changes.

\section{Conclusion}

To create the architectural style of Harbin should emphasize its context. Harbin has many western architectural works of different times, so better management, protection and development of these cultural relics architectures is the biggest urban characteristics of Harbin. The biggest characteristics of Harbin is diversified Russian style architectures. When protecting, and promoting the unique architectures, the coordination of architectural function and urban planning and development should be considered at first. Through the protection and renewal of Russian style architecture in Harbin, to promote the development of Harbin in the future and retain its original architecture culture connotation at the same time, it is necessary to formulate corresponding sustainable development and protection measures of urban architecture. The government departments should pay more attention to how to deal with the relationship between architecture and city planning, the contradiction of new architectures and ancient architectures. To develop reasonably and to make the linkage between the old and new architectures form rationally. To specify different standards for different areas to improve the process of Harbin in sustainable development, and to entry into the rank of modernize city as soon as possible.

\section{References}

[1]. Jiang Xue, The Influence of Russian Architectural Style on Architectural Image of Harbin, Harbin University of Science and Technology, 2011

[2]. Liu Songfu, The Cultural Structure and Context of Modern Harbin Architectures, New Architecture, 2002

[3]. Liu Yuhan, The Research on Chinese Baroque Architecture in Daoli District of Harbin, Northeast Forestry University, 2013

[4]. Liu Songfu, The Culture Representation of Modern Harbin Architectures, College journal of Harbin Construction University, 2002

[5]. He Ying, The Aesthetic Research on the Outside Decoration of Modern Harbin Architecture, Harbin Institute of Technology, 2012 